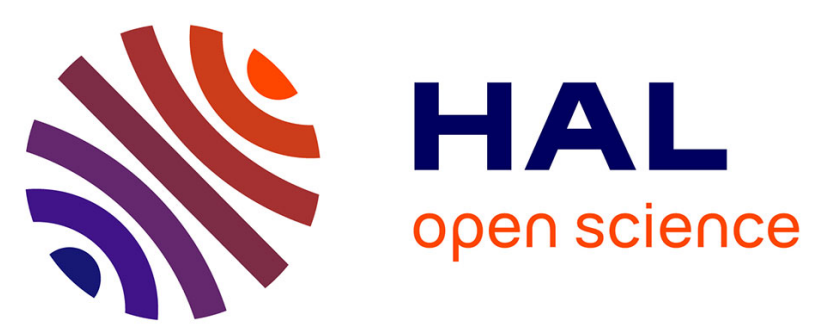

\title{
Effect of locomotor training on muscle performance in the context of nerve-muscle communication dysfunction
}

Wahiba Hadj-Said, Marie Bangratz, Alban Vignaud, Arnaud Chatonnet, Gillian Butler-Browne, Sophie Nicole, Onnick Agbulut, Arnaud Ferry

\section{- To cite this version:}

Wahiba Hadj-Said, Marie Bangratz, Alban Vignaud, Arnaud Chatonnet, Gillian Butler-Browne, et al. Effect of locomotor training on muscle performance in the context of nerve-muscle communication dysfunction. Muscle \& Nerve, 2012, 45 (4), pp.567-577. 10.1002/mus.22332 . hal-01545457

\author{
HAL Id: hal-01545457 \\ https://hal.science/hal-01545457
}

Submitted on 29 May 2020

HAL is a multi-disciplinary open access archive for the deposit and dissemination of scientific research documents, whether they are published or not. The documents may come from teaching and research institutions in France or abroad, or from public or private research centers.
L'archive ouverte pluridisciplinaire HAL, est destinée au dépôt et à la diffusion de documents scientifiques de niveau recherche, publiés ou non, émanant des établissements d'enseignement et de recherche français ou étrangers, des laboratoires publics ou privés. 
EFFECT OF LOCOMOTOR TRAINING ON MUSCLE PERFORMANCE IN THE CONTEXT OF NERVE-MUSCLE COMMUNICATION DYSFUNCTION

\author{
WAHIBA HADJ-SAÏD, MSc, ${ }^{1,2,3,4}$ MARIE BANGRATZ, PhD, $, 5,6$ ALBAN VIGNAUD, PhD, ${ }^{1,2,3,4}$ ARNAUd CHATONNET, PhD, ${ }^{8}$ \\ GILLIAN BUTLER-BROWNE, PhD, ${ }^{1,2,3,4}$ SOPHIE NICOLE, PhD, ${ }^{5,6,7,9}$ ONNICK AGBULUT, PhD, ${ }^{10}$ \\ and ARNAUD FERRY, PhD ${ }^{\mathbf{1 , 2 , 3 , 4 , 1 1}}$ \\ ${ }^{1}$ Université Pierre et Marie Curie-Paris, UMR-S974, Paris F-75013, France \\ ${ }^{2}$ INSERM, U974, Paris, France \\ ${ }^{3}$ CNRS, UMR 7215, Paris, France \\ ${ }^{4}$ Institut de Myologie, Paris, France \\ ${ }^{5}$ Université Pierre et Marie Curie-Paris, Centre de Recherche de l'Institut du Cerveau et de la Moelle épinière, \\ UMR-S 975, Paris, France \\ ${ }^{6}$ INSERM, U975, Paris, France \\ ${ }^{7}$ CNRS, UMR 7225, Paris, France \\ ${ }^{8}$ Université de Montpellier, INRA UMR 866 DMEM, Montpellier, France \\ ${ }^{9}$ Assistance Publique-Hôpitaux de Paris, Département de Neurologie \& centre de référence "canalopathies musculaires," Groupe \\ Hospitalier de la Pitié-Salptrière, Paris, France \\ ${ }^{10}$ Université Paris Diderot, Sorbonne Paris Cité, CNRS EAC 4413, Unit of Functional and Adaptive Biology, Laboratory of Stress and \\ Pathologies of the Cytoskeleton, Paris, France \\ ${ }^{11}$ Université Paris Descartes, Sorbonne Paris Cité Paris, France \\ Accepted 17 October 2011
}

ABSTRACT: Introduction: The effects of locomotor training (LT) on skeletal muscle after peripheral nerve injury and acetylcholinesterase deficiency are not well documented. Methods: We determined the effects of LT on mouse soleus muscle performance after sciatic nerve transection with excision (full and permanent denervation), nerve transection (partial functional reinnervation), nerve crush (full denervation with full functional reinnervation), and acetylcholinesterase deficiency (alteration in neuromuscular junction functioning). Results: We found no significant effect of LT on the recovery of soleus muscle weight, maximal force in response to muscle stimulation, and fatigue resistance after nerve transection with or without excision. However, LT significantly increased soleus muscle fatigue resistance after nerve crush and acetylcholinesterase deficiency. Moreover, hindlimb immobilization significantly aggravated the deficit in soleus muscle maximal force production and atrophy after nerve crush. Conclusions: LT is beneficial, and reduced muscle use is detrimental for intrinsic muscle performance in the context of disturbed nerve-muscle communication.

Muscle Nerve 45: 567-577, 2012

Peripheral nerve injury induces skeletal muscle inactivity by disrupting nerve-muscle communication. It leads to muscle atrophy and reduction in maximal force production in response to both nerve and muscle stimulation, ${ }^{1-3}$ because maximal force is roughly proportional to muscle size. Although damaged axons of motoneurons are capable of regeneration, muscle fiber reinnervation is often suboptimal, leading to muscle weakness.

Abbreviations: AChE, acetylcholinesterase; CSA, cross-sectional area; $K O$, knockout; $L_{f}$, fiber length; LT, locomotor training; $L_{0}$, optimal length; MHC-1, myosin heavy chain type 1; mTOR, mammalian target of rapamycin; MuRF, muscle RING-finger protein-1; NC, nerve crush; NMJ, neuromuscular junction; NT, nerve transaction; NTWR, nerve transaction without repair; PBS, phosphate-buffered saline; $P_{0}$, maximal isometric force; $\mathrm{SP}_{0}$, specific maximal force; Runx1, runt-related trascription factor; TA, tibialis anterior; WT, wild-type

Key words: nerve injury, exercise, skeletal muscle, acetylcholinesterase deficiency, maximal force, fatigue resistance

Correspondence to: A. Ferry; e-mail: arnaudferry@upmc.fr

(C) 2011 Wiley Periodicals, Inc.

Published online 21 October 2011 in Wiley Online Library

(wileyonlinelibrary.com). DOI 10.1002/mus.22332

Exercise, Nerve, and Muscle
Consequently, different strategies have been used to improve or accelerate nerve regeneration and muscle reinnervation after nerve injury. Increased neuromuscular activity via physical exercise, such as locomotor training (LT) and electrostimulation, have been shown to improve nerve regeneration and muscle reinnervation, as assessed using histological measures ${ }^{4-9}$ and analysis of coordinated and complex motor functions, namely toe-spreading reflex and locomotion. ${ }^{6,10}$ Together these earlier studies suggested that increased neuromuscular activity may improve the full recovery of muscle performance after nerve injury, such as maximal force production.

Various diseases that affect the neuromuscular junction (NMJ) also alter nerve-muscle communication, such as congenital myasthenic syndromes. Absence or reduced level of acetylcholinesterase (AChE) at the neuromuscular junction impairs neuromuscular functioning, because AChE hydrolyzes acetylcholine (ACh) and prevents ACh accumulation with desensitization of ACh receptors. ${ }^{11}$ Accordingly, muscles from knockout (KO) AChE mice are unable to maintain force production in response to repetitive nerve stimulation, regardless of frequency. ${ }^{11,12}$ Perlecan mutant mice were recently generated by introducing a missense mutation into the Hspg2 gene that encodes perlecan. ${ }^{13}$ Perlecan mutant mice with an $80 \%$ reduction of synaptic AChE are still able to maintain force production but not at lower frequencies $(12.5$ and $25 \mathrm{~Hz})$ of nerve stimulation. ${ }^{13}$ This severe neuromuscular fatigability ${ }^{11,13,14}$ would markedly reduce the normal level of muscle activity of a postural and motor muscle such as the soleus muscle. Therefore, it is not surprising that absence of AChE causes muscle atrophy and 
reduction in maximal force, ${ }^{14}$ as it does in denervation $^{15}$ and physical inactivity. ${ }^{16}$ To reduce the muscle weakness induced by AChE deficiency, it is of interest to determine whether increased neuromuscular activity would have a beneficial effect on muscle performance.

To examine the effect of increased neuromuscular activity on intrinsic muscle performance after peripheral nerve injury, we investigated the effects of regular locomotor training on muscle maximal force production in response to muscle stimulation, fatigue resistance, and weight in normal mice after nerve injury. We studied recovery of the soleus muscle after sciatic nerve injury because it is an antigravity muscle that is heavily recruited during locomotion. Our first hypothesis was that LT would improve muscle performance after nerve injuries that allow muscle reinnervation (nerve transection alone or crush), because muscle inactivity reduces contractility ${ }^{15,16}$ and increased neuromuscular activity improves or accelerates nerve regeneration and muscle reinnervation. ${ }^{4-10}$ Second, we examined whether LT would improve the performance of the permanently denervated soleus muscle (nerve transection with excision), as it was recently demonstrated that mechanical signals coming from passive stretch could reduce atrophy of denervated muscle ${ }^{17}$ and thus, possibly, the deficit in maximal force production. Moreover, we studied the effect of LT on soleus muscle contractility of mice that exhibit permanent disturbed neuromuscular junction functioning due to AChE deficiency at the neuromuscular junction. Our third hypothesis was that LT would improve soleus muscle performance of AChE-deficient mice exhibiting severe neuromuscular fatigability, ${ }^{11,13,14}$ because reduced muscle activity leads to muscle weakness. ${ }^{15,16}$ All these experiments were aimed to provide information on the potential beneficial effect of exercise on muscle weakness observed in the case of neuromuscular diseases affecting nerve-muscle communication.

\section{METHODS}

Animals. All procedures were performed in accordance with national and European legislation on animal experimentation. Bilateral nerve transection or nerve crush were performed in adult male wild-type (WT) CD1 mice. Nerve transection without possible repair (NTWR) was done by removal of up to $10 \mathrm{~mm}$ of the sciatic nerve, to prevent reinnervation after axotomy. In the case of transection with possible nerve repair [nerve transaction (NT)], the sciatic nerves were cut, and the cut ends of the nerve were aligned and glued. The gap between the two cut ends did not exceed $2 \mathrm{~mm}$. Sciatic nerves were crushed (NC) $5 \mathrm{~mm}$ proximal to their bifurcation twice for $5 \mathrm{~s}$ each with a fine forceps. Mice were analyzed at different timepoints after NTWR, NT, and NC at 4.5 months of age. Age-matched WT mice were used as innervated/intact (nerve uninjured) mice. In addition, the right and left hindlimbs of some WT mice were immobilized 2 days after NC. The ankle joints were immobilized in maximal plantarflexion to shorten the soleus, as described elsewhere. ${ }^{18,19} \mathrm{We}$ also studied male adult (3-4-month-old) perlecan mutant mice ${ }^{13}$ and KO AChE ${ }^{12,14}$ mice exhibiting AChE deficiency at the neuromuscular junction compared with littermate WT mice. No body weight difference was found between groups.

Locomotor Training (Exercise). Transected and crushed WT mice that received locomotor training (LT) were trained 5 days/week, starting on postoperative day 2. They were trained on a motorized treadmill (walking and running). The duration of the training session was increased from 45 to 120 min during 1 month, while the speed was increased from 5 to $15 \mathrm{~cm} / \mathrm{s}$. Due to hip motility, WT mice continue to use the hindlimb after nerve transection or crush. Perlecan mutant mice ran up to $1 \mathrm{~h}$ /day (5 days per week) during 1 month at a speed that was increased from 10 to $30 \mathrm{~cm} / \mathrm{s}$. The beginning of each training session consisted of a warm-up (15 $\mathrm{min}$ at $5 \mathrm{~cm} / \mathrm{s}$ for the transected and crushed WT mice or $15 \mathrm{~min}$ at $5-15 \mathrm{~cm} / \mathrm{s}$ for the perlecan mutant mice).

Muscle Performance and Functional Innervation. The isometric contractile properties of soleus muscles were studied in vitro as previously described. ${ }^{14,15}$ Mice were euthanized after removal of soleus muscles. Muscles were soaked in an oxygenated Krebs solution $\left(95 \% \mathrm{O}_{2}\right.$ and $\left.5 \% \mathrm{CO}_{2}\right)$ containing $58.5 \mathrm{mM} \mathrm{NaCl}, 24 \mathrm{mM} \mathrm{NaHCO}, 5.4 \mathrm{mM} \mathrm{KCl}, 1.2$ $\mathrm{mM} \mathrm{KH}{ }_{2} \mathrm{PO}_{4}, 1.8 \mathrm{mM} \mathrm{CaCl}_{2}, 1 \mathrm{mM} \mathrm{MgSO}_{4}$, and $10 \mathrm{mM}$ glucose ( $\mathrm{pH} \mathrm{7.4)}$, and maintained at a temperature of $22^{\circ} \mathrm{C}$. One of the muscle tendons was attached to a force transducer (Harvard). After equilibration (30 min), electrical stimulation was delivered through electrodes running parallel to the muscle. One-millisecond pulses were generated by a high-power stimulator (701B; Aurora Scientific). Maximal isometric force $\left(\mathrm{P}_{0}\right)$ was measured during isometric contractions in response to electrical stimulation (frequency of 50-125 Hz, train of stimulation of $1500 \mathrm{~ms}$ ). All measurements were made at optimal muscle length $\left(\mathrm{L}_{0}\right.$, length at which $\mathrm{P}_{0}$ was obtained). Fatigue resistance was determined after a 5-min rest period. The muscles were stimulated at $75 \mathrm{~Hz}$ during $500 \mathrm{~ms}$ every $1.6 \mathrm{~s}$ for $3 \mathrm{~min}$. The time taken for initial force to fall by $30 \%$ (FR) was determined. The soleus muscles were weighed, and specific maximal force $\left(\mathrm{sP}_{0}\right)$ 
was calculated by dividing $\mathrm{P}_{0}$ by the estimated cross-sectional area (CSA) of the muscle. Assuming muscles have a cylindrical shape and a density of $1.06 \mathrm{mg} / \mathrm{mm}^{3}$, the CSA corresponds to the volume of the muscle divided by fiber length $\left(\mathrm{L}_{\mathrm{f}}\right)$. The $\mathrm{L}_{\mathrm{f}}$ to $\mathrm{L}_{0}$ ratio of 0.70 was used to calculate $\mathrm{L}_{\mathrm{f}}$.

The isometric contractile properties of tibialis anterior (TA) muscles were also studied in situ as previously described. ${ }^{12}$ The knee and foot were fixed using clamps and pins. The distal tendons of the TA muscles were attached to a force transducer (Harvard). $\mathrm{P}_{0}$ was measured during isometric contractions in response to electrical stimulation (frequency of 75-150 Hz, train of stimulation of $500 \mathrm{~ms}$ ). The sciatic nerve (proximally crushed) was stimulated by a bipolar silver electrode using a supramaximal square-wave pulse of $0.1-\mathrm{ms}$ duration. Then, muscles were directly stimulated using supramaximal current. The comparison of the nerve and muscle responses allows us to evaluate functional muscle innervation, a marker of muscle reinnervation after nerve injury. TA muscles were weighed, and specific force $\left(\mathrm{sP}_{0}\right)$ was calculated by dividing $\mathrm{P}_{0}$ by muscle weight.

Histology. Transverse serial sections of muscles ( 8 $\mu \mathrm{m})$ were obtained using a cryostat in the midbelly region. The muscles were sectioned at different intervals to determine the maximal muscle CSA, and the corresponding sections were studied. Some of the sections were processed for hematoxylin-eosin and succinate dehydrogenase (SDH) staining, according to standard protocols. Quantification of SDH staining was performed using image analysis of staining intensity of the muscle crosssection. Other sections were used for immunohistochemistry, as previously described. ${ }^{15,20}$ For determination of muscle fiber type, frozen unfixed sections were blocked for $1 \mathrm{~h}$ in a blocking solution (bovine serum albumin 4\%, IgG free) and incubated overnight with a mouse monoclonal antibody directed against myosin heavy chain type 1 (MHC-1; 1/50; Hybridoma Bank). After washes in phosphate-buffered saline (PBS), sections were incubated for $1 \mathrm{~h}$ with secondary Alexa Fluor-conjugated anti-mouse IgG (1/400; Molecular Probes). After washes in PBS, slides were finally mounted in Fluoromont (Dako). To quantify capillary density, endothelial cells were immunostained with antiCD31 antibody (1/50; Clone MEC13.3; BD Pharmingen). Serial sections of muscles were captured using a digital camera (Hamamatsu ORCA-AG) attached to a motorized fluorescence microscope (AxioImager.Z1; Zeiss). For fiber type analysis, capillary density, and SDH staining quantifications, all of the muscle fibers of the muscle section were measured.

\section{Nerve transection without repair (soleus)}
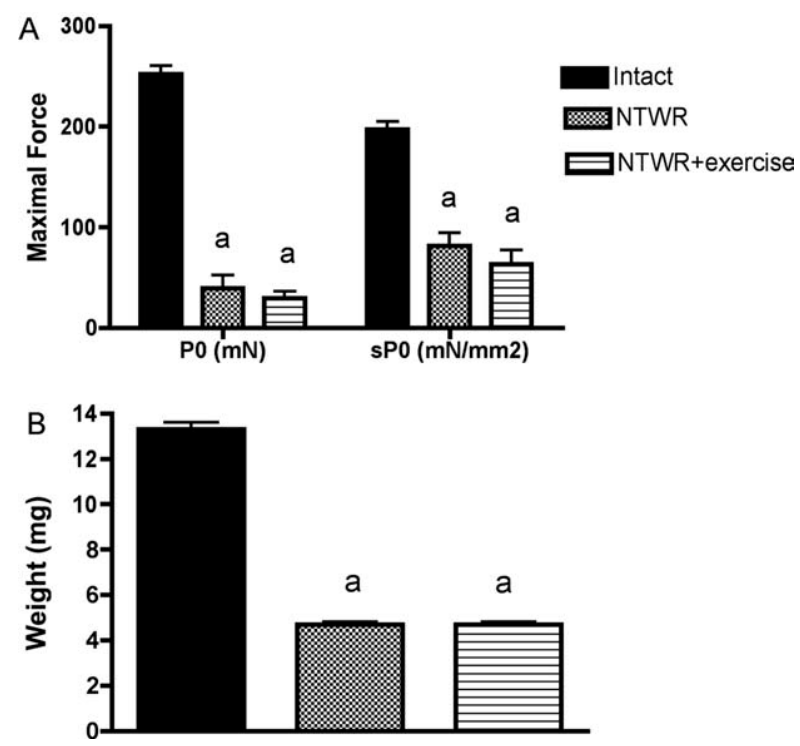

FIGURE 1. Absolute (PO) and specific ( $\mathrm{SP} 0$ ) maximal forces (A) and weight (B) of soleus muscles 1 month after nerve transection without possible repair. Values are mean \pm SEM. Number per group $=10-12$. NTWR, nerve transection without possible repair. ${ }^{\text {aS }}$ ignificantly different from intact $(P<0.05)$.

Statistical Analysis. Groups were compared using one-way analysis of variance. $P<0.05$ was considered significant. Subsequent post hoc analysis was performed when required. Data are expressed as mean \pm SEM.

\section{RESULTS}

Nerve Transection without Possible Repair. We first determined whether LT would improve muscle performance after nerve transection without possible repair (NTWR), that is, permanent denervation, in adult WT mice. Sciatic nerves were transected with removal of around $10 \mathrm{~mm}$ of the sciatic nerves. The mice were trained on a motorized treadmill over 1 month before measurements of soleus muscle performance were made. NTWR resulted in marked decreases in both absolute $(-84 \%, P<0.05)$ and specific $(\times 59 \%, P<0.05)$ maximal force production in response to soleus muscle stimulation (Fig. 1A). The muscle was also atrophic, because muscle weight was reduced $(-65 \%, P<0.05$; Fig. 1B). The TA was less affected by NTWR than the soleus, an antigravity muscle. In fact, the TA exhibited a smaller reduction in absolute maximal force $(-56 \%, P<0.05)$ and weight $(-26 \%, P<0.05)$ after NTWR than the soleus (data not shown). With regard to the effect of LT, we found that it did not significantly reduce the loss of soleus maximal force and weight induced by NTWR, as there was no significant difference between trained and untrained NTWR mice (Fig. 1A and B). These results indicate that 


\section{A Nerve transection (soleus)}
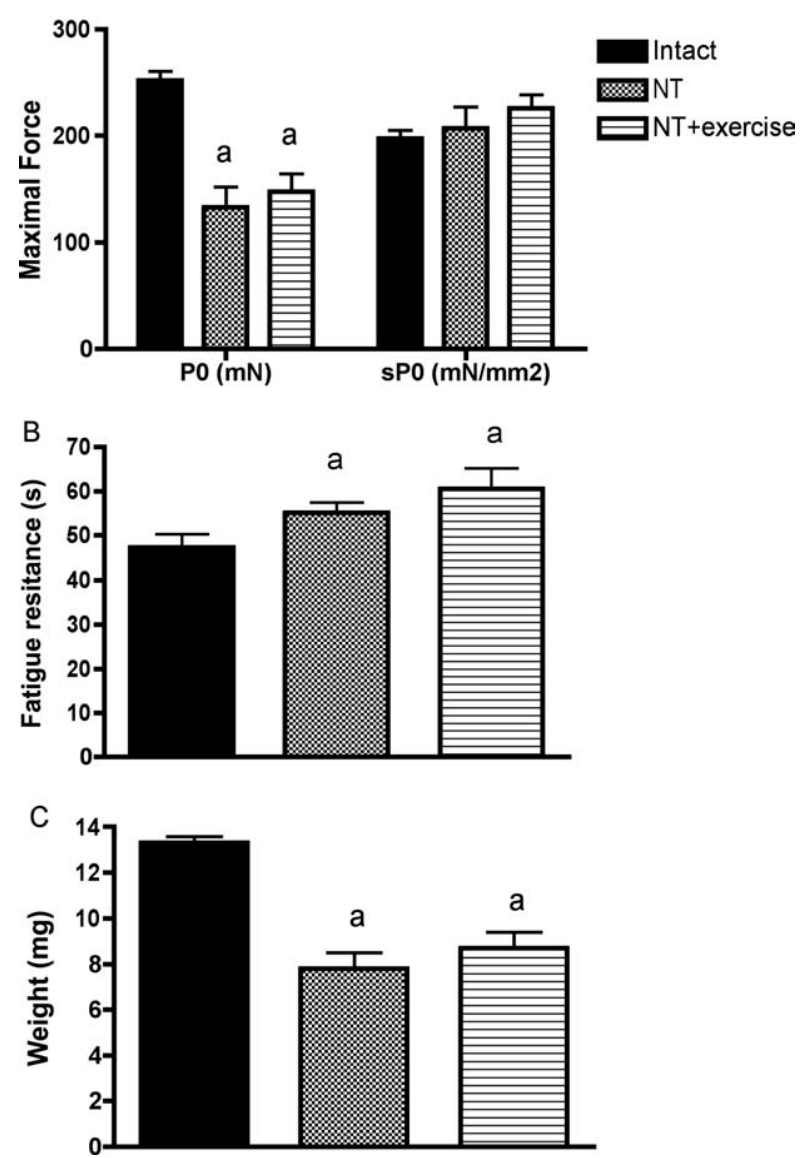

FIGURE 2. Absolute (PO) and specific (SP0) maximal forces (A), fatigue resistance (B), and weight (C) of soleus muscles 2 months after nerve transection. Values are mean \pm SEM. Num-

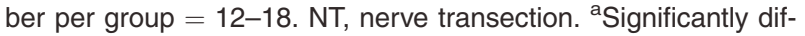
ferent from intact $(P<0.05)$.

1-month LT had no effect on the performance of permanently denervated muscle.

Nerve Transection. We then asked whether LT had a beneficial impact on muscle performance after nerve transection with possible repair (NT). The cut ends of the sciatic nerves were aligned and glued, and the mice were trained on a motorized treadmill during 2 months. We confirmed that partial muscle reinnervation did occur, because there was substantial force production in response to nerve stimulation. Indeed, functional muscle innervation reached $69.0 \pm 4.0 \%(P<$ $0.05)$ in untrained and $67.2 \pm 5.1 \%(P<0.05)$ in trained NT mice as compared with $102.2 \pm 2.3 \%$ in intact mice, with no significant difference between trained and untrained NT mice. Functional muscle innervation is the maximal force production in response to nerve stimulation expressed as percentage of the force production in response to muscle stimulation (stimulation bypassing nerve-muscle communication). For the determina- tion of functional muscle innervation, we studied only the TA, because soleus forces obtained in response to nerve and muscle stimulations were too low to be recorded in situ.

At 2 months after NT, the soleus showed reduced absolute maximal force $(-47 \%, P<0.05$; Fig. 2A) and muscle weight $(-41 \%, P<0.05$; Fig. $2 \mathrm{C})$, but no significant change in specific maximal force $(P>$ 0.05 ; Fig. 2A). Fatigue resistance was increased by NT $(+16 \%, P<0.05$; Fig. 2B). LT did not improve muscle characteristics after NT. In fact, muscle weight, absolute and specific maximal forces, and fatigue resistance did not differ significantly between trained and untrained NT mice (Fig. 2A-C). In addition, no beneficial LT effect was obtained for the TA after NT. The deficits of absolute $(-55 \%$ and $-57 \% ; P<0.05)$ and specific $(-29 \%$ and $-16 \%, P$ $<0.05)$ maximal force production in response to muscle stimulation of the TA were not significantly different in untrained and trained NT mice (Fig. 3A). Moreover, TA atrophy was significantly increased by LT in NT mice (untrained $-50 \%$, trained $-60 \%, P<0.05$; Fig. 3B).

Nerve Crush. In the following experiments, we first determined whether LT would improve muscle performance after nerve crush injury (NC) in WT mice. NC allowed a greater recovery of nervemuscle communication compared with NT, because functional muscle innervation recovered
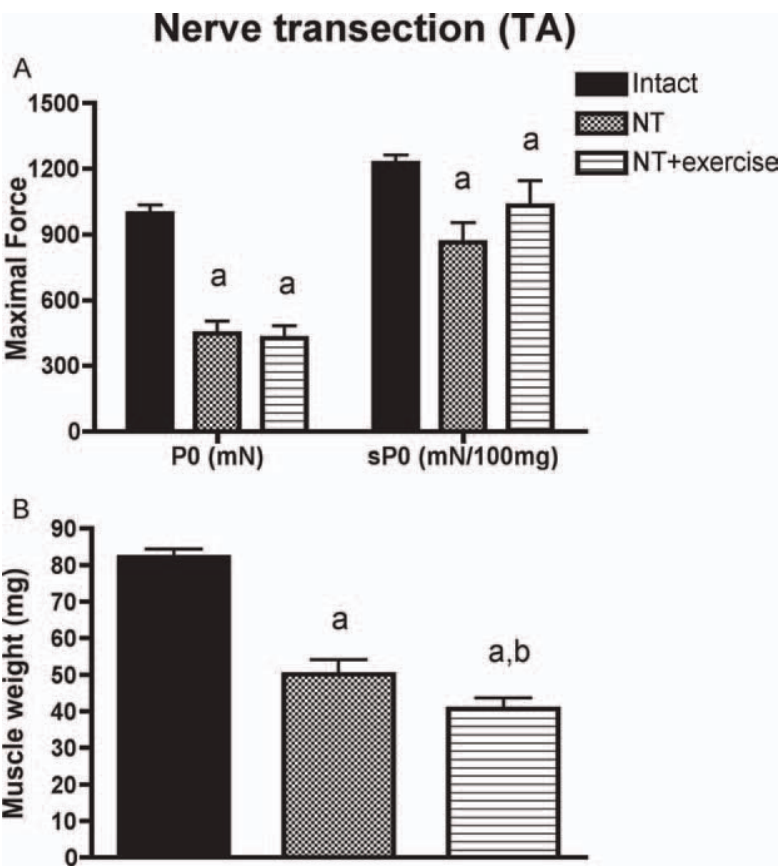

FIGURE 3. Absolute (PO) and specific (sP0) maximal forces (A) and weight (B) of TA muscles 2 months after nerve transection. Values are mean \pm SEM. Number per group $=12-18$. NT, nerve transection. ${ }^{a}$ Significantly different from intact $(P<$ $0.05)$; ${ }^{b}$ significantly different from NT $(P<0.05)$. 


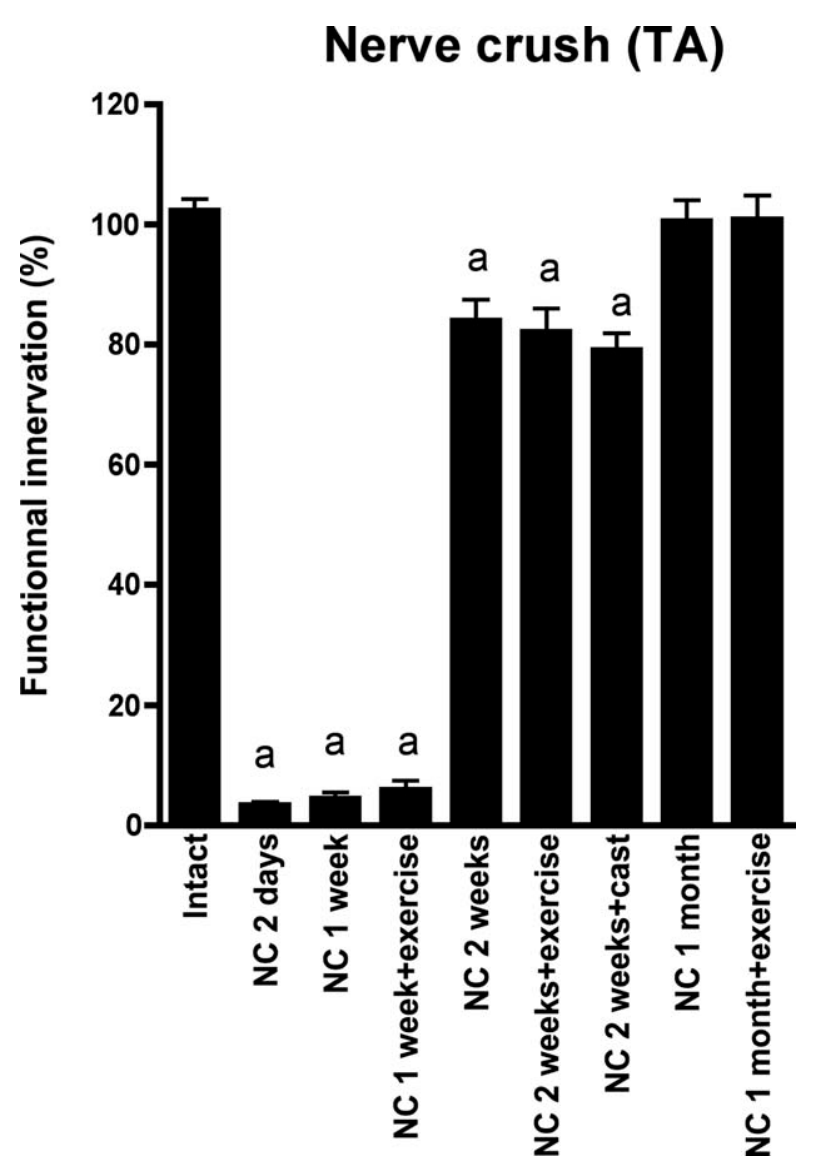

FIGURE 4. Functional muscle innervation 2 days, 1 week, 2 weeks, and 1 month after nerve crush. TA muscle force production in response to nerve stimulation is expressed relative to force production in response to muscle stimulation. Number per group $=6-18$. NC, nerve crush. ${ }^{\text {aS }}$ ignificantly different from intact $(P<0.05)$.

fully at 1 month after NC (Fig. 4). Of note, there was no effect of LT on functional muscle innervation (Fig. 4).

By 2 weeks after $\mathrm{NC}$, reduction in absolute $(-30 \%$ and $-33 \%, P<0.05)$ and specific $(-17 \%$ and $-16 \%, P<0.05)$ soleus maximal force in response to muscle stimulation (Fig. 5A), decreased fatigue resistance $(-22 \%$ and $-21 \%$, $P<0.05$; Fig. 5B), and atrophy $(-27 \%$ and $-33 \%$, $P<0.05$; Fig. 5C) were observed, but there was no significant difference between untrained and trained NC mice. In addition, we also found no beneficial effect of LT on the TA at 2 weeks after NC. The deficit of absolute $(-30 \%$ and $-23 \%$, $P<0.05)$ maximal force production in response to muscle stimulation of the TA was also not significantly different in trained and untrained NC mice (Fig. 6A). The decrease in specific maximal force (untrained $-17 \%$, trained $-7 \%, P<0.05$; Fig. $6 \mathrm{~A}$ ) was significantly reduced by LT because muscle atrophy was increased (untrained $-11 \%$ vs. trained $-21 \%, P<0.05)$ in NC mice (Fig. 6B).
By 1 month after NC, there was a reduction in absolute maximal force $(-24 \%, P<0.05)$ in response to muscle stimulation (Fig. 7A), with modest soleus atrophy $(-11 \%, P<0.05$; Fig. 7C) . Specific maximal force (Fig. 7A) and fatigue resistance (Fig. 7B) were not significantly reduced 1 month after NC. Moreover, the extent of loss of absolute maximal force (Fig. 7A) and soleus

\section{Nerve crush 2 weeks (soleus) Intact NC 2 weeks}

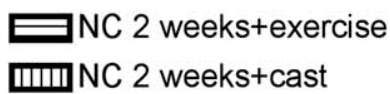

A
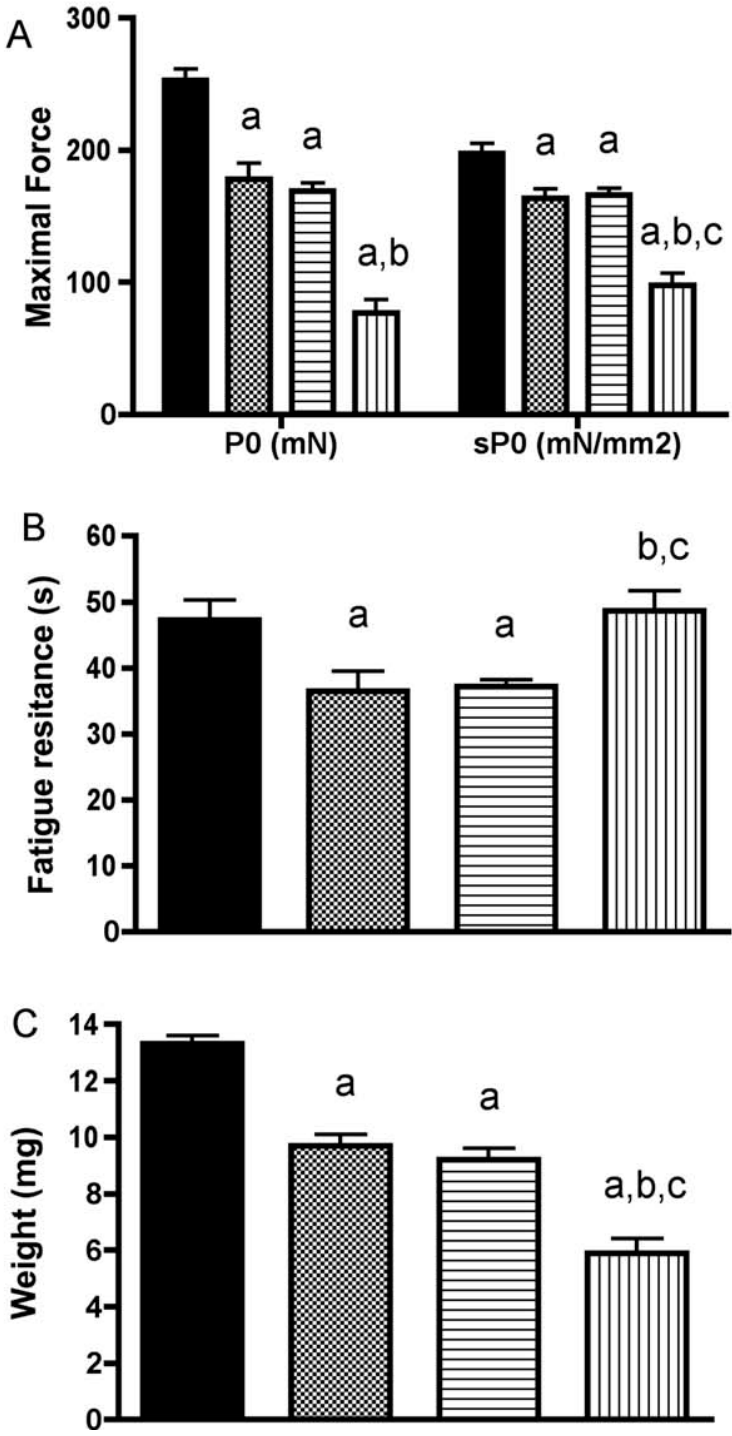

FIGURE 5. Absolute (PO) and specific ( $\mathrm{SPO}$ ) maximal forces (A), fatigue resistance (B), and weight (C) of soleus muscles 2 weeks after nerve crush. Values are mean \pm SEM. Number per group $=10-18$. NC, nerve crush. ${ }^{\text {aS }}$ Significantly different from intact $(P<0.05)$; ${ }^{b}$ significantly different from NC $(P<$ $0.05)$; 'significantly different from NC + exercise $(P<0.05)$. 


\section{Nerve crush 2 weeks (TA)}

A

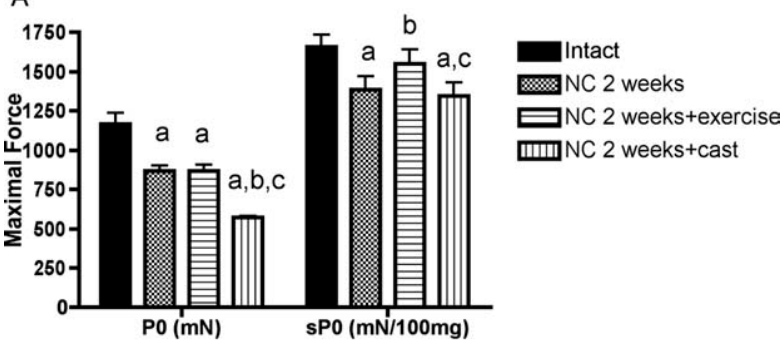

B

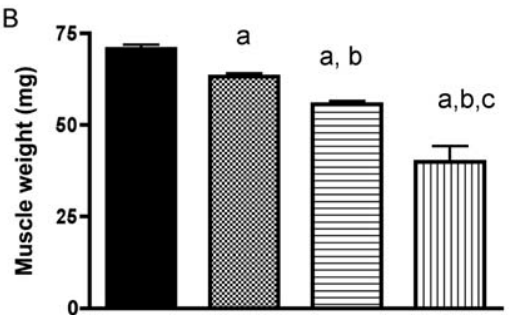

FIGURE 6. Absolute (PO) and specific ( $\mathrm{SPO}$ ) maximal forces (A) and weight (B) of TA muscles 2 weeks after nerve crush. Values are mean \pm SEM. Number per group $=10-18$. NC, nerve crush. ${ }^{a}$ Significantly different from intact $(P<0.05)$; ${ }^{\mathrm{b}}$ significantly different from NC $(P<0.05)$; ${ }^{\mathrm{C}}$ significantly different from $\mathrm{NC}+$ exercise $(P<0.05)$.

muscle atrophy (Fig. 7C) were not significantly different between trained and untrained $\mathrm{NC}$ mice. However, 1-month LT increased fatigue resistance by $54 \%$ in NC mice $(P<0.05$; Fig. $7 \mathrm{~B})$. Because it is well established that slow/oxidative fibers are more fatigue-resistant than fast/glycolytic fibers, ${ }^{21}$ we performed muscle fiber type analysis. We found that the increased fatigue resistance was not associated with a change in SDH staining (Fig. 8A and B), a marker of oxidative metabolism, with a higher percentage of fibers expressing MHC-1 (slow fibers; Fig. 8A and B) or increased capillary density (Fig. 8C) in trained NC mice as compared with untrained NC mice. In addition, there was no difference in absolute or specific maximal force responses to muscle stimulation and weight of the TA muscle between untrained, trained, and intact NC mice (data not shown).

Finally, we sought to determine whether a normal level of physical activity is essential for muscle performance recovery after NC in WT mice. During recovery after NC, hindlimbs were immobilized using plaster casts in WT mice. Immobilization was performed during the first 2 weeks after NC, during which we found no effect of LT. At 2 weeks after NC, hindlimb immobilization significantly worsened the deficit in soleus muscle absolute $(-70 \%)$ and specific $(-50 \%)$ maximal forces (Fig. 5A) in response to muscle stimulation, and muscle atrophy (-55\%; Fig. 5C). Similarly, it increased the deficit in absolute maximal force $(P<0.05$; Fig. 6A) in response to muscle stimulation and weight $(P<0.05$; Fig. $6 \mathrm{~B})$ of TA muscle from NC mice. Interestingly, we found that these detrimental changes induced by hindlimb immobilization were not significantly associated with changes in functional muscle innervation (Fig. 4).

AChE Deficiency. We aimed to determine whether LT would ameliorate the soleus muscle performance observed in congenital conditions with

\section{Nerve crush 1 month (soleus)}

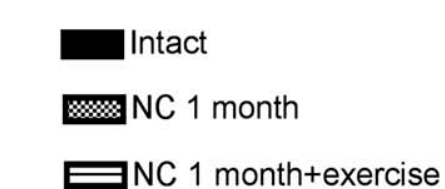

A

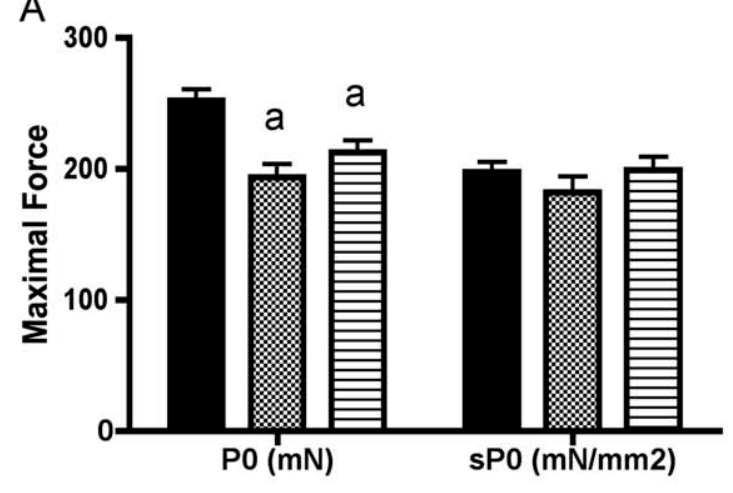

a, b
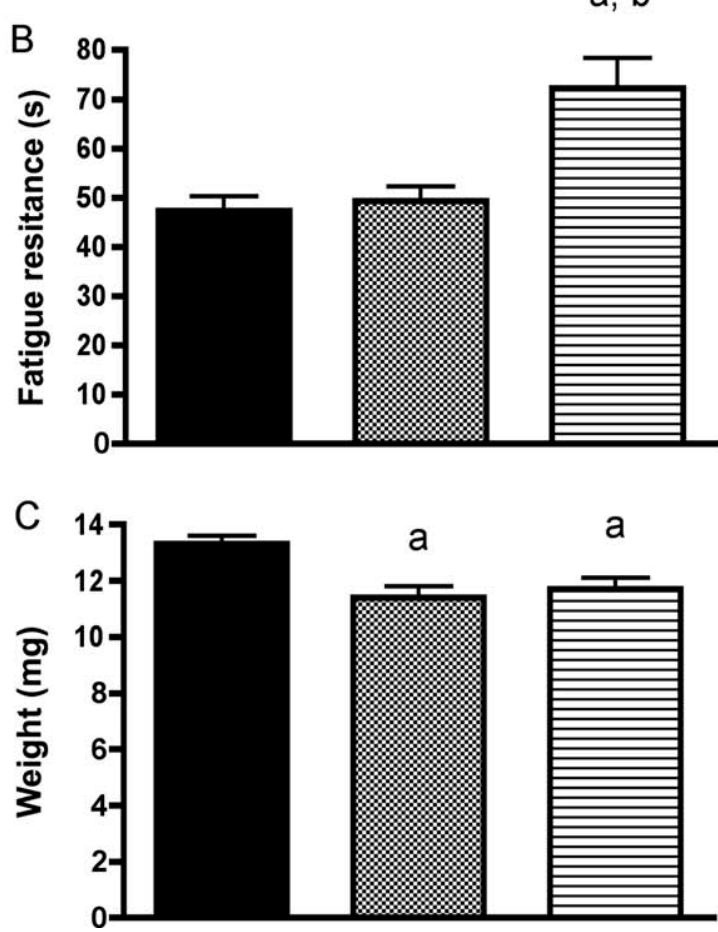

FIGURE 7. Absolute (PO) and specific (SP0) maximal forces (A), fatigue resistance (B), and weight $(\mathbf{C})$ of soleus muscles 1 month after nerve crush. Values are mean \pm SEM. Number per

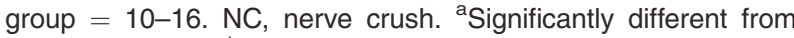
intact $(P<0.05)$; ${ }^{\text {b }}$ significantly different from NC $(P<0.05)$. 


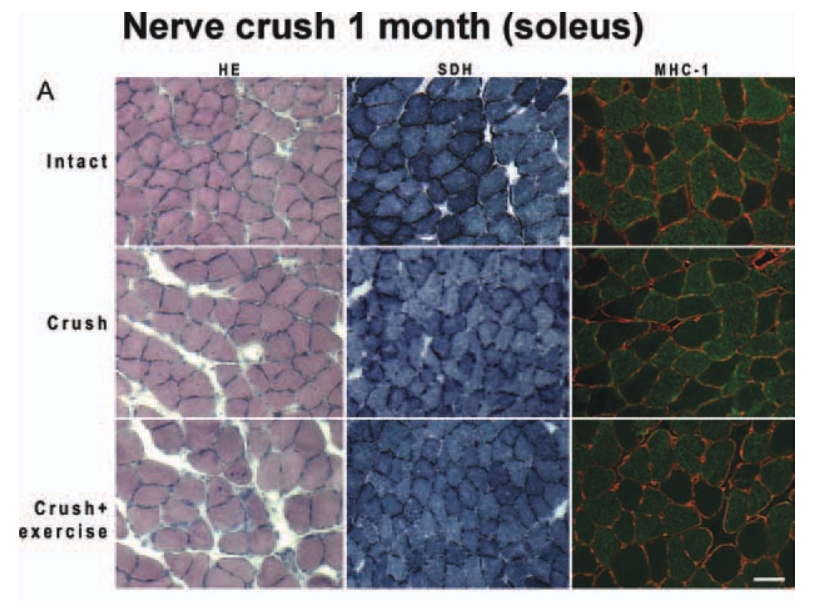

B
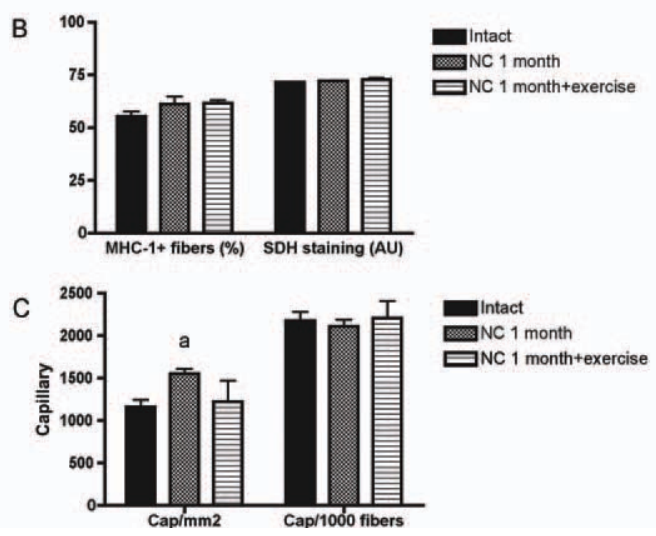

FIGURE 8. Histological analysis of soleus muscles 1 month after nerve crush. (A) Representative cross-sectional images are shown: sections were stained with hematoxylin and eosin (HE) or with succinate dehydrogenase (SDH) or for MHC-1 reactivity (MHC-1). Bar $=50 \mu \mathrm{m}$ for HE and SDH staining; bar $=40 \mu \mathrm{m}$ for MHC-1. (B) The percentage of fibers expressing MHC-1 and $\mathrm{SDH}$ staining quantification are shown. Values are mean \pm SEM $(n=4)$. (C) Numbers of capillaries per square millimeter and per 1000 fibers are shown. Values are mean $\pm \operatorname{SEM}(n=4)$. [Color figure can be viewed in the online issue, which is available at wileyonlinelibrary.com.]

altered neuromuscular transmission and neuromuscular fatigability (tetanic fade). ${ }^{11-13}$ For this purpose, we investigated two murine models with synaptic AChE deficiency: AChE KO and perlecan mutant mice. In a previous study we showed that there was soleus muscle weakness in AChE KO mice (data not shown). ${ }^{14}$ In the present study, we found that soleus muscle from perlecan mutant mice also exhibited reduced muscle performance. In 3.5-month-old perlecan mutant mice, there were deficits in soleus absolute $(-29 \%)$ and specific $(-19 \%)$ maximal force production in response to muscle stimulation, weight $(-18 \% ; P$ $<0.05$; Fig. 9) and fatigue resistance $(-40 \% ; P<$ 0.05; Fig. 10) when compared with littermate WT mice. The muscle deficit was confirmed in older perlecan mutant mice, as absolute maximal forces were $145.0 \pm 8.0 \mathrm{mN}$ and $241.9 \pm 12.7 \mathrm{mN}$ $(-40 \%, P<0.05)$ in 23-month-old perlecan mutant and WT mice, respectively.
We then tested whether LT might improve this phenotype in young adult AChE KO and perlecan mutant mice. Unfortunately, it was not possible to do locomotor training in adult AChE KO mice more than 3 days before they refused to walk on the motorized treadmill. This was confirmed by the fact that the voluntary activity of the AChE KO mice is insignificant compared with WT mice, as measured during the 2-week period when the mice were housed individually in cages equipped with running wheels (data not shown). Therefore, we only show data pertaining to perlecan mutant mice. We found that 1-month LT had no significant effect on the deficit in absolute and specific maximal forces in response to muscle stimulation (Fig. 9A) and muscle atrophy of soleus muscles from 3.5-month-old perlecan mutant mice (Fig. 9B). However, as reported for WT mice with NC, LT increased $(+223 \%)$ fatigue resistance $(P<$ 0.05; Fig. 10A and B). This was not associated with a difference between trained and untrained perlecan mutant mice in SDH staining, and the

\section{Perlecan (soleus)}

Wild-type

Perlecan mutant

PPerlecan mutant+exercise

A
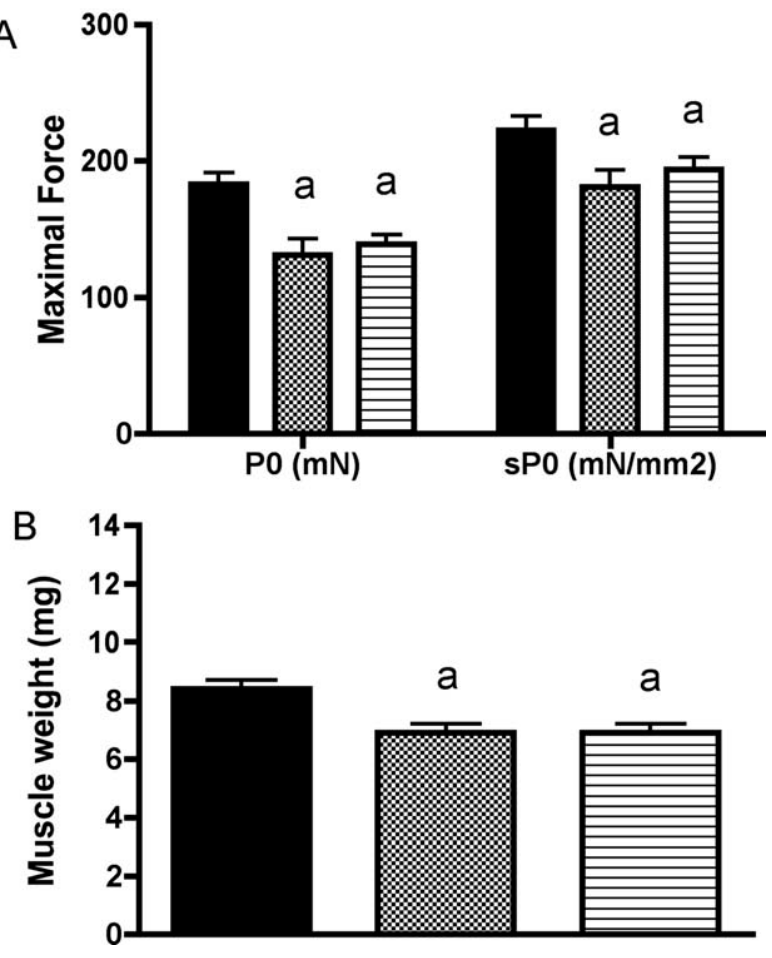

FIGURE 9. Absolute ( $\mathrm{PO}$ ) and specific ( $\mathrm{SPO}$ ) maximal forces (A) and weight (B) of soleus muscles from perlecan mutant mice. Values are mean \pm SEM. Number per group $=8$. ${ }^{\text {a Signi- }}$ ficantly different from wild-type $(P<0.05)$. 


\section{Perlecan (soleus)}
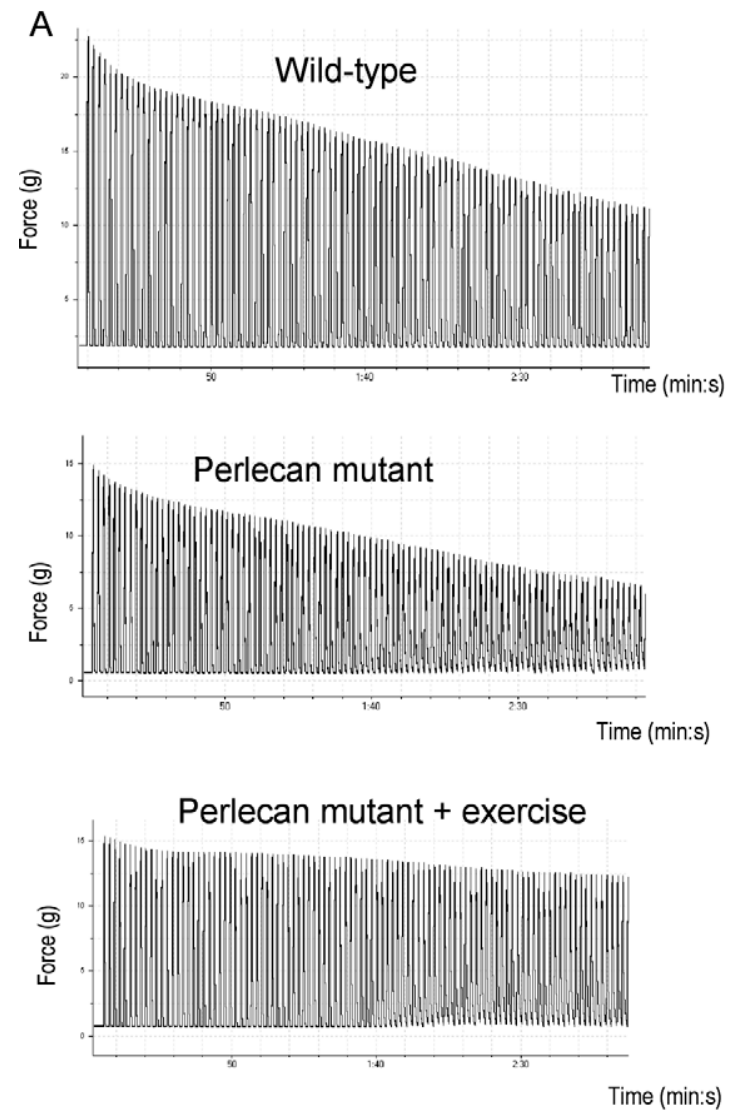

B

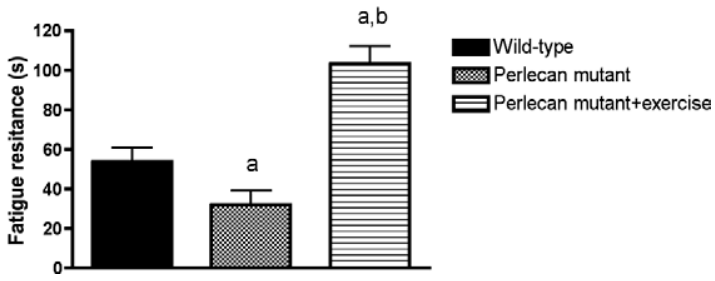

FIGURE 10. Fatigue resistance of soleus muscles from perlecan mutant mice. (A) Representative force recordings. (B) Fatigue resistance index. Values are mean \pm SEM. Number per

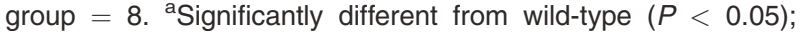
${ }^{\mathrm{b}}$ significantly different from perlecan mutant $(P<0.05)$.

percentage of fibers expressing MHC-1 (Fig. 11A and B). However, the capillary density (capillary/ $\left.\mathrm{mm}^{2}\right)$ was increased by LT $(P<0.05)$, whereas the capillary/fiber ratio was unchanged (Fig. 11C).

\section{Discussion}

In this investigation we determined whether LT would improve intrinsic muscle performance in mouse models with alterations of nerve-muscle communication. Although much attention has been focused on neural and synaptic aspects, less attention has been focused on the functional aspects of the target skeletal muscle. We sought to determine whether LT could be beneficial in these pathological situations, as suggested by several studies that addressed nerve regeneration and muscle reinnervation or the effect of muscle inactivity.

LT Had No Effect when Fully Functional Innervation Did Not Occur. We found that NTWR, that is, permanent denervation, markedly impaired muscle performance and reduced muscle weight. This is in line with previous studies that examined soleus and TA muscles in mice. ${ }^{15,22}$ The deficit in absolute maximal force $(-84 \%)$ was caused by both a reduced specific maximal force and a lower soleus muscle weight. We also observed that the effect of denervation was more severe for the soleus than the TA $(-84 \%$ vs. $-56 \%$ for absolute maximal force), confirming previous studies. ${ }^{23}$ This difference may be explained by the fact that the soleus contains both slow and fast fibers, whereas the TA contains only fast fibers, with the assumption that

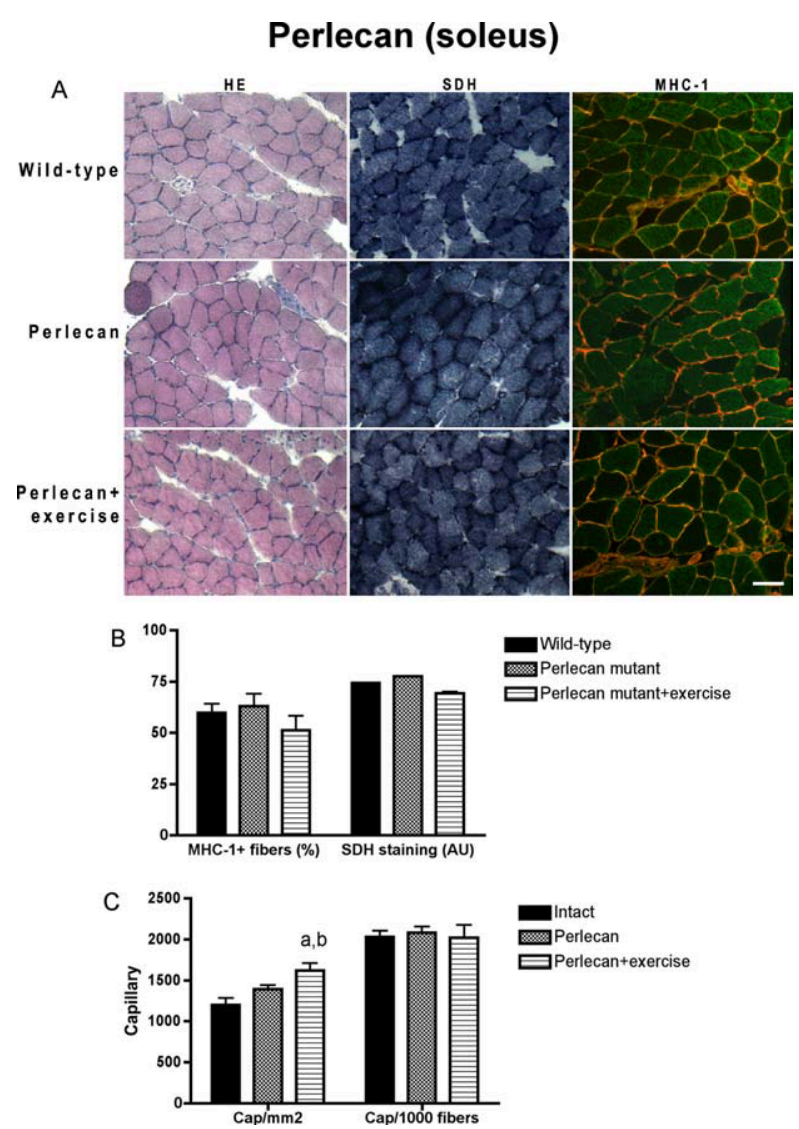

FIGURE 11. Histological analysis of soleus muscles from perlecan mice. (A) Representative cross-sectional images are shown: sections were stained with hematoxylin and eosin (HE) or with succinate dehydrogenase $(\mathrm{SDH})$ or for $\mathrm{MHC}-1$ reactivity (MHC-1). Bar $=50 \mu \mathrm{m}$ for HE and SDH staining; bar $=40 \mu \mathrm{m}$ for MHC-1. (B) The percentage of fibers expressing MHC-1 and $\mathrm{SDH}$ staining quantification are shown. Values are mean \pm SEM $(n=4)$. (C) Numbers of capillaries per square millimeter and per 1000 fibers are shown. Values are mean \pm SEM $(n=$

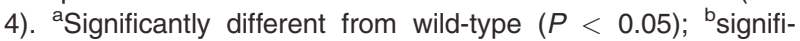
cantly different from perlecan mutant $(P<0.05)$. [Color figure can be viewed in the online issue, which is available at wileyonlinelibrary.com.] 
slow fibers are more sensitive to permanent denervation than fast fibers. However, our previous study reported that slow and fast soleus fibers had equally reduced CSA in response to permanent denervation $(-47 \%$ and $-37 \%) .^{15}$ More likely, this differential effect of denervation results from the fact that the antigravity soleus muscle is more active than the TA muscle, ${ }^{24}$ thus confirming that analysis of the effect of LT on the soleus is pertinent.

It was recently demonstrated that mechanical signals coming from passive stretch could reduce the atrophy of denervated muscle. ${ }^{17}$ In denervated and atrophied muscle, passive stretching activates Akt and downstream targets of mammalian targetof-rapamycin (mTOR) involved in protein synthesis; reduces the upregulation of atrogin-1 and muscle RING-finger protein-1 (MuRF1), which are activators of protein degradation; and maintains the level of runt-related transcription factor-1 (Runx1), which controls autophagy. ${ }^{17,25}$ Moreover, constitutively activated Akt prevents muscle atrophy caused by denervation. ${ }^{26}$ Therefore, we hypothesized that LT would attenuate muscle atrophy and thus weakness induced by NTWR via activation of Akt/mTOR signaling induced by repeated muscle stretching during locomotor training, because maximal force is roughly proportional to muscle size. However, our results clearly indicate that LT did not improve denervated soleus muscle function and atrophy after NTWR, confirming very recent studies that examined only muscle atrophy. ${ }^{25,27}$ There is a possibility is that LT in denervated hindlimb muscles did not result in enough muscle stretching because of the altered gait pattern, as assessed, for example, by the sciatic functional index. ${ }^{28}$

Although muscle better recovered compared with NTWR, we observed that there was still a muscle deficit 2 months after NT for soleus and TA. The explanation for the marked muscle deficit (absolute maximal force is reduced by -47\%) is that functional innervation did not recover fully, indicating that all muscle fibers were not reinnervated and/or that nerve-muscle communication was not able to fully activate muscle. It should also be noted that fatigue resistance was curiously increased after NT. One possibility is that atrophy ameliorates fiber wash-out, attenuating the metabolite accumulation responsible for fatigue. With regard to $\mathrm{LT}$, our results show that it did not have a beneficial effect on soleus and TA muscle performance after NT. Therefore, our findings suggest that the possible increased nerve regeneration induced by LT or electrostimulation observed by histological analysis ${ }^{4,8,9}$ has no major impact on muscle weakness and functional innervation. Discrepancies between nerve histology, motor function, and electrophysiology measures have been reported to occur during muscle reinnervation. ${ }^{29}$

LT Increased Fatigue Resistance but Immobilization Was Detrimental after Nerve Crush Injury. One month after NC, we found only a moderate soleus muscle deficit (absolute maximal force is reduced by $-24 \%$ ), which was much lower than that observed after NT. This differential did not result from a difference in acute denervation, because nerve-muscle communication was similarly disrupted 2 days after both nerve injuries. The explanation for this is the greater recovery of functional innervation after NC than after NT (100.5\% vs. $69 \%$ ). In contrast to NT, NC leaves the basal lamina intact, allowing the axonal sprouts to grow within the Schwann cell bands. ${ }^{28}$ Our results also indicate that LT did not reduce the deficit of maximal force and muscle weight in soleus 1 month after NC. However, LT increased fatigue resistance, and this effect was not caused by a greater functional innervation in trained NC mice. Because the increased fatigue resistance was not yet observed at 2 weeks after NC, it appears that LT had a significant effect only in almost fully reinnervated fibers. LT could increase fatigue resistance in NC muscle via the activation of signaling pathways upregulating mitochondrial biogenesis, oxidative metabolism, angiogenesis, and promotion of fast-to-slow fiber transition as in intact muscle. ${ }^{30}$ However, our data pertaining to SDH staining (a marker of oxidative metabolism), the percentage of slow/fatigue-resistant fibers, and capillary density do not support this hypothesis.

Despite the fact that LT had no effect during the first 2 weeks after NC, we also showed that hindlimb immobilization markedly increased the deficit in maximal force and weight of soleus and TA 2 weeks after NC. These results are in line with previous data showing that reduced use (activity) of the hindlimb decreases maximal force production by rat gastrocnemius muscle after $\mathrm{NC}^{3}{ }^{3}$ It should be also noted that immobilization did not affect muscle functional innervation. Together, our findings indicate that normal activity is required for the recovery of muscle performance after nerve injury, and reinnervated muscle can be trained to improve its performance.

Beneficial Effect of LT on Fatigue Resistance in the Case of AChE Deficiency. Finally, we tested whether LT would improve muscle performance in pathological conditions with abnormal neuromuscular transmission. Perlecan is a major component of basement membranes and plays a critical role at the neuromuscular junction by anchoring AChE to the synaptic basement membrane. ${ }^{13,31}$ Perlecan deficiency results in Schwartz-Jampel syndrome, a 
human recessive disorder with peripheral nerve hyperexcitability. ${ }^{32,33}$ We recently demonstrated abnormal neuromuscular transmission with muscle fatigability (tetanic fade) at low frequency of nerve stimulation in perlecan-deficient muscle. ${ }^{13}$ Here we have shown that perlecan mutant soleus muscle exhibits atrophy and lower muscle performance (absolute and specific maximal forces, fatigue resistance) than WT muscle. Similar muscle weakness was observed in the soleus from $\mathrm{KO} A C h E$ mice ${ }^{14}$; for instance, absolute maximal forces are reduced by $-29 \%$ and $-31 \%$ in the soleus in perlecan mutant and KO AChE mice, respectively. The muscle deficit induced by AChE deficiency is likely the result of disturbed nerve-muscle communication leading to extreme fatigability, whereas muscle functional innervation is unchanged, ${ }^{12}$ in contrast to NTWR, NT, and NC.

Similar to its effects after NC, LT increased the fatigue resistance of perlecan mutant soleus muscle without reducing the deficit in absolute maximal force. The increased fatigue resistance induced by LT is independent from the promotion of slow/ oxidative fibers in perlecan mutant mice. One possibility is that LT attenuated tetanic fade and allowed the muscle to be more durably active and to therefore be trained, such as with the almost fully reinnervated muscle after NC (see earlier). There is evidence that the NMJ adapts to increased muscle use, such as LT, at least in wild-type rodents. $^{34,35}$ Exercise induces synaptic remodeling $^{35}$ that could contribute to a better diffusion of ACh. Moreover, neuromuscular transmission in the soleus from WT mice is enhanced by LT, via a reduced rundown of endplate potential during high-frequency continuous nerve stimulation, ${ }^{34}$ an event that is exaggerated in AChE-deficient mice. ${ }^{36}$ It would be of interest in the future to confirm the effect of LT using another animal model of perturbed neurotransmission.

In conclusion, we have shown that LT enhanced fatigue resistance in reinnervated muscles (1 month after nerve crush) and innervated muscles with AChE deficiency (perlecan mutant mice), but it had no effect when muscle was even partially denervated (nerve transection with excision, nerve transection alone, and 2 weeks after nerve crush). Of note, LT was not able to reduce the deficit in muscle maximal force and atrophy observed after nerve injury or AChE deficiency, possibly because the program of muscle contractions resulting from LT is not appropriate. ${ }^{37}$ We also observed that reduced muscle use aggravated the muscle deficit in maximal force and atrophy after nerve injury. Moreover, we found that LT and muscle disuse did not change muscle functional innervation. Taken together, our results help to rationalize the choice of therapeutic approaches, because they show that increased physical activity could be beneficial to muscle performance of patients with neuromuscular diseases affecting nerve-muscle communication, and that inactivity should be avoided.

The authors are grateful to Yvain Caudéran and Isabelle Lachaize for technical assistance during the experiments. This study was financially supported by Université Pierre et Marie Curie (UPMC), CNRS, INSERM, University Paris Descartes, ANR-Genopath In-AFib, ANR-Blanc Androgluco, the Association Française contre les Myopathies (AFM), MyoAge (EC 7th FP, Contract No. 223576), and Agence Française de Lutte contre le Dopage.

\section{REFERENCES}

1. Blondet B, Carpentier G, Ferry A, Courty J. Exogenous pleiotrophin applied to lesioned nerve impairs muscle reinnervation. Neurochem Res 2006;31:907-913.

2. Irintchev A, Draguhn A, Wernig A. Reinnervation and recovery of mouse soleus muscle after long-term denervation. Neuroscience 1990;39:231-243.

3. Matsuura T, Ikata T, Takata S, Kashiwaguchi S, Niwa M, Sogabe T, et al. Effect of weight bearing on recovery from nerve injury in skeletal muscle. J Appl Physiol 2001;91:2334-2341.

4. Asensio-Pinilla E, Udina E, Jaramillo J, Navarro X. Electrical stimulation combined with exercise increase axonal regeneration after peripheral nerve injury. Exp Neurol 2009;219:258-265.

5. Goldshmit Y, Lythgo N, Galea MP, Turnley AM. Treadmill training after spinal cord hemisection in mice promotes axonal sprouting and synapse formation and improves motor recovery. J Neurotrauma 2008;25:449-465.

6. Ilha J, Araujo RT, Malysz T, Hermel EE, Rigon P, Xavier LL, et al. Endurance and resistance exercise training programs elicit specific effects on sciatic nerve regeneration after experimental traumatic lesion in rats. Neurorehabil Neural Repair 2008;22:355-366.

7. Molteni R, Zheng JQ, Ying Z, Gomez-Pinilla F, Twiss JL. Voluntary exercise increases axonal regeneration from sensory neurons. Proc Natl Acad Sci USA 2004;101:8473-8478.

8. Sabatier MJ, Redmon N, Schwartz G, English AW. Treadmill training promotes axon regeneration in injured peripheral nerves. Exp Neurol 2008;211:489-493.

9. Udina E, Puigdemasa A, Navarro X. Passive and active exercise improve regeneration and muscle reinnervation after peripheral nerve injury in the rat. Muscle Nerve 2011;43:500-509.

10. Sebille A, Bondoux-Jahan M. Effects of electric stimulation and previous nerve injury on motor function recovery in rats. Brain Res 1980;193:562-565

11. Adler M, Manley HA, Purcell AL, Deshpande SS, Hamilton TA, Kan RK, et al. Reduced acetylcholine receptor density, morphological remodeling, and butyrylcholinesterase activity can sustain muscle function in acetylcholinesterase knockout mice. Muscle Nerve 2004; 30:317-327.

12. Mouisel E, Blondet B, Escourrou P, Chatonnet A, Molgo J, Ferry A Outcome of acetylcholinesterase deficiency for neuromuscular functioning. Neurosci Res 2006;55:389-396.

13. Stum M, Girard E, Bangratz M, Bernard V, Herbin M, Vignaud A, et al. Evidence of a dosage effect and a physiological endplate acetylcholinesterase deficiency in the first mouse models mimicking Schwartz-Jampel syndrome neuromyotonia. Hum Mol Genet 2008; 17:3166-3179.

14. Vignaud A, Fougerousse F, Mouisel E, Guerchet N, Hourde C, Bacou F, et al. Genetic inactivation of acetylcholinesterase causes functional and structural impairment of mouse soleus muscles. Cell Tissue Res 2008;333:289-296.

15. Agbulut O, Vignaud A, Hourde C, Mouisel E, Fougerousse F, ButlerBrowne GS, et al. Slow myosin heavy chain expression in the absence of muscle activity. Am J Physiol Cell Physiol 2009;296:C205-214.

16. Salazar JJ, Michele DE, Brooks SV. Inhibition of calpain prevents muscle weakness and disruption of sarcomere structure during hindlimb suspension. J Appl Physiol 2010;108:120-127.

17. Agata N, Sasai N, Inoue-Miyazu M, Kawakami K, Hayakawa K, Kobayashi K, et al. Repetitive stretch suppresses denervation-induced atrophy of soleus muscle in rats. Muscle Nerve 2009;39:456-462.

18. Frimel TN, Kapadia F, Gaidosh GS, Li Y, Walter GA, Vandenborne $\mathrm{K}$. A model of muscle atrophy using cast immobilization in mice. Muscle Nerve 2005;32:672-674.

19. Shah SB, Peters D, Jordan KA, Milner DJ, Friden J, Capetanaki Y, et al. Sarcomere number regulation maintained after immobilization 
in desmin-null mouse skeletal muscle. J Exp Biol 2001;204: 1703-1710.

20. Trollet C, Anvar SY, Venema A, Hargreaves IP, Foster K, Vignaud A, et al. Molecular and phenotypic characterization of a mouse model of oculopharyngeal muscular dystrophy reveals severe muscular atrophy restricted to fast glycolytic fibers. Hum Mol Genet 2010;19: 2191-2207.

21. Burke RE, Levine DN, Tsairis P, Zajac FE III. Physiological types and histochemical profiles in motor units of the cat gastrocnemius. J Physiol 1973;234:723-748.

22. Raffaello A, Laveder P, Romualdi C, Bean C, Toniolo L, Germinario E, et al. Denervation in murine fast-twitch muscle: short-term physiological changes and temporal expression profiling. Physiol Genomics 2006;25:60-74.

23. Webster DM, Bressler $\mathrm{BH}$. Changes in isometric contractile properties of extensor digitorum longus and soleus muscles of C57BL/6J mice following denervation. Can J Physiol Pharmacol 1985;63: 681-686.

24. Hodgson JA, Roy RR, Higuchi N, Monti RJ, Zhong H, Grossman E, et al. Does daily activity level determine muscle phenotype? J Exp Biol 2005;208:3761-3770.

25. Russo TL, Peviani SM, Durigan JL, Gigo-Benato D, Delfino GB, Salvini TF. Stretching and electrical stimulation reduce the accumulation of MyoD, myostatin and atrogin-1 in denervated rat skeletal muscle. J Muscle Res Cell Motil 2010;31:45-57.

26. Bodine SC, Latres E, Baumhueter S, Lai VK, Nunez L, Clarke BA, et al. Identification of ubiquitin ligases required for skeletal muscle atrophy. Science 2001;294:1704-1708.

27. Jakubiec-Puka A, Slawinska U, Redowicz MJ, Biral D, Lapinska I, Chomontowska $\mathrm{H}$, et al. Influence of locomotor training on the structure and myosin heavy chains of the denervated rat soleus muscle. Neurol Res 2008;30:170-178.
28. Griffin JW, Pan B, Polley MA, Hoffman PN, Farah MH. Measuring nerve regeneration in the mouse. Exp Neurol 2010;223:60-71.

29. Munro CA, Szalai JP, Mackinnon SE, Midha R. Lack of association between outcome measures of nerve regeneration. Muscle Nerve 1998;21:1095-1097.

30. Schiaffino S, Sandri M, Murgia M. Activity-dependent signaling pathways controlling muscle diversity and plasticity. Physiology (Bethesda) 2007;22:269-278.

31. Arikawa-Hirasawa E, Rossi SG, Rotundo RL, Yamada Y. Absence of acetylcholinesterase at the neuromuscular junctions of perlecan-null mice. Nat Neurosci 2002;5:119-123.

32. Echaniz-Laguna A, Rene F, Marcel C, Bangratz M, Fontaine B, Loeffler JP, et al. Electrophysiological studies in a mouse model of Schwartz-Jampel syndrome demonstrate muscle fiber hyperactivity of peripheral nerve origin. Muscle Nerve 2009;40:55-61.

33. Nicole S, Davoine CS, Topaloglu H, Cattolico L, Barral D, Beighton $\mathrm{P}$, et al. Perlecan, the major proteoglycan of basement membranes, is altered in patients with Schwartz-Jampel syndrome (chondrodystrophic myotonia). Nat Genet 2000;26:480-483.

34. Desaulniers P, Lavoie PA, Gardiner PF. Habitual exercise enhances neuromuscular transmission efficacy of rat soleus muscle in situ. J Appl Physiol 2001;90:1041-1048.

35. Wilson MH, Deschenes MR. The neuromuscular junction: anatomical features and adaptations to various forms of increased, or decreased neuromuscular activity. Int J Neurosci 2005;115:803-828.

36. Minic J, Chatonnet A, Krejci E, Molgo J. Butyrylcholinesterase and acetylcholinesterase activity and quantal transmitter release at normal and acetylcholinesterase knockout mouse neuromuscular junctions. Br J Pharmacol 2003;138:177-187.

37. Dow DE, Cederna PS, Hassett CA, Kostrominova TY, Faulkner JA, Dennis RG. Number of contractions to maintain mass and force of a denervated rat muscle. Muscle Nerve 2004;30:77-86. 